\title{
Signal Peptide Peptidases and \\ Gamma-Secretase: Cousins of the Same Protease Family?
}

\author{
Regina Fluhrer Christian Haass \\ Adolf-Butenandt-Institute, Department of Biochemistry, Laboratory for Alzheimer's and \\ Parkinson's Disease Research, Ludwig-Maximilians University, Munich, Germany
}

\section{Key Words}

Alzheimer's disease • Presenilin • Signal peptide peptidase • GxGD proteases $\cdot$ Regulated intramembrane cleavage

\begin{abstract}
Signal peptide peptidase (SPP) is an unusual aspartyl protease, which mediates clearance of signal peptides by proteolysis within the endoplasmic reticulum (ER). Like presenilins, which provide the proteolytically active subunit of the $\gamma$-secretase complex, SPP contains a conserved GxGD motif in its C-terminal domain which is critical for its activity. While SPP is known to be an aspartyl protease of the GxGD type, several presenilin homologues/SPP-like proteins (PSHs/ SPPL) of unknown function have been identified by database searches. In contrast to SPP and SPPL3, which are both restricted to the endoplasmic reticulum, SPPL2b is targeted through the secretory pathway to endosomes/lysosomes. As suggested by the differential subcellular localization of SPPL $2 \mathrm{~b}$ and SPPL3 distinct phenotypes were found upon antisense gripNA-mediated knockdown in zebrafish. spp and spp/3 knockdowns in zebrafish result in cell death within the central nervous system, whereas reduction of spp/2b expression causes erythrocyte accumulation in an enlarged caudal vein. Moreover, expression of D/A mutants of the putative C-terminal active sites of $s p p$, spp/2, and spp/3 produced phenocopies of the respective knockdown phenotypes. These data suggest that all investigated PSHs/SPPLs are members
\end{abstract}

of the novel family of GxGD aspartyl proteases. More recently, it was shown that SPPL2b utilizes multiple intramembrane cleavages to liberate the TNF $\alpha$ intracellular domain into the cytosol and to release the C-terminal counterpart into the lumen. These findings suggest common principles of intramembrane proteolysis by GxGD type aspartyl proteases. In this article, we will review the similarities of SPPs and $\gamma$-secretase based on recent findings by us and others.

Copyright $\odot 2007$ S. Karger AG, Basel

\section{Introduction}

Intramembrane proteolysis is mediated by a class of novel polytopic proteases, which have their active centers located within the hydrophobic transmembrane domains $[1,2]$. Members of these proteases include the site-2-protease (S2P) [1], rhomboids [3, 4], $\gamma$-secretase [5], and signal peptide peptidase (SPP) $[6,7]$. While S2P and rhomboids belong to the class of metallo- and serine proteases, respectively, $\gamma$-secretase and SPP are aspartyl proteases $[2,8,9]$.

The catalytic core of $\gamma$-secretase is provided by either of the two homologous presenilins (PS1 or PS2). Co-factors including APH-1, PEN-2, and Nicastrin are absolutely required to generate a functional $\gamma$-secretase complex [1014]. PS1 or PS 2 containing $\gamma$-secretase complexes can both mediate the intramembrane cleavage of the $\beta$-amyloid

\section{KARGER}

Fax +4161306 1234

E-Mail karger@karger.ch

www.karger.com
(C) 2007 S. Karger AG, Basel

$1660-2854 / 07 / 0043-0112 \$ 23.50 / 0$

Accessible online at:

www.karger.com/ndd
Christian Haass

Adolf-Butenandt-Institute, Department of Biochemistry

Laboratory for Alzheimer's and Parkinson's Disease Research

Ludwig-Maximilians University, DE-80336 Munich (Germany)

Tel. +49 89218075 472, Fax +4989 218075 415, E-Mail chaass@med.uni-muenchen.de 
precursor protein (APP), Notch and probably many other type 1-oriented substrates as well [8,15-18] suggesting functional redundancy. The C-terminal critical aspartate of PSs is located within a conserved GxGD motif [19], whereas the $\mathrm{N}$-terminal aspartate is embedded within a YD sequence segment. The GxGD signature motif is highly conserved in SPP, an unrelated polytopic aspartyl protease $[2,7,20,21]$ as well as in the type 4 prepilin peptidases (TFPP) $[19,22]$. Moreover, mutagenesis of the corresponding aspartate residue completely blocks the proteolytic activity of SPP [7], PS1 [5], PS2 [15, 23], and TFPP [22].

The facts that active site inhibitors of $\gamma$-secretase can be cross-linked to presenilins $[24,25]$ and bind to presenilins in dependence of the critical aspartate [26], suggest that the aspartate within the GxGD motif comprises the $\mathrm{C}$-terminal active site of these proteases. Besides this highly conserved active site, further similarities are observed between PSs, SPP, and TFPPs, which for example include a PxL motif within the C-terminal domain.

SPP is required for the removal of signal peptides after their liberation by signal peptidase during translocation of proteins into the endoplasmic reticulum [2]. In addition, SPP is also involved in immune surveillance and processing of the Hepatitis viral core protein [7] suggesting a more general role of SPP in the liberation of bioactive peptides $[2,7,20,21]$. Besides SPP a family of homologous proteins was identified by database searches $[2,7$, $20,27,28]$. These proteins were named SPPL (SPP-like) 2 (a,b,c) and 3 (in yeast an additional SPPL, SPPL4, exists) [7], PSHs 1-5 [27] or IMPASes [28]. For clarity, we will use the term SPPL throughout this work. Although SPPLs share some homology with SPP, it is not known if they exhibit any proteolytic activity [21]. Here, we will briefly summarize the recent findings on the cellular function of SPP family members and then compare these data to the well defined $\gamma$-secretase biology.

\section{All SPPs Are Members of the GxGD Family of Aspartyl Proteases}

The catalytically critical aspartate residue of SPP, TFPPs, PS1 and PS2 $[2,9,19,22]$ is embedded within a GxGD motif, which is also fully conserved in all SPPLs. Together with the aspartate of the equally critical N-terminal YD motif [5, 29], these are the only aspartate residues, which are fully conserved throughout the SPPs, SPPLs, PSs, and TFPPs. Moreover, Weihofen et al. [7] mutagenized the conserved aspartate residue 265 within the GxGD motif of SPP and found that SPP D265A lost its proteolytic activity. As shown for PS1, a transition state inhibitor, known to block $\gamma$-secretase activity via binding to its active site also blocks SPP function [30]. This fits well with the mutagenesis of the corresponding aspartate residues within the GxGD motif of PS1, PS2 [5, 15, 23] and TFPP [22], which all lost their entire proteolytic activity upon mutagenesis of the aspartate. Thus, the corresponding aspartate residues within the GxGD motif of SPPLs may likely be responsible for their catalytic function as putative aspartyl proteases. To investigate the functional significance of the corresponding aspartate in SPPLs in vivo and to provide evidence that SPPLs are aspartyl proteases, this amino acid was mutated in SPP and its homologues to alanine and the resultant phenotype was compared to that of corresponding knockdowns in zebrafish [31]. spp and sppl3 knockdowns in zebrafish result in cell death within the central nervous system, whereas reduction of $s p p l 2 b$ expression causes erythrocyte accumulation in an enlarged caudal vein. Strikingly, expression of D/A mutations of the putative C-terminal active sites of $s p p$, sppl2, and $s p p l 3$ produced phenocopies of the respective knockdown phenotypes. This strongly suggests a functional role of the GxGD domain in SPPLs, and makes it very likely that SPPLs also belong to the family of GxGD aspartyl proteases.

\section{Finding Substrates for the SPPL-Protease Family}

To finally prove that SPPLs are indeed proteases, it is essential to find substrates being turned over by the proteases. For SPP it has been suggested that only type 2oriented transmembrane proteins may be accepted as substrates [7, 32, 33]. Furthermore, Martoglio and coworkers postulated that the critical aspartates of the active site in SPP/SPPLs are oriented in the opposite direction to those of PSs in the $\gamma$-secretase complex $[2,7]$, which only cleave type 1 transmembrane proteins [10]. Consequently, a type 2 transmembrane protein located to late endosomale compartments could be a good candidate substrate for SPPL2a and SPPL2b. Indeed, the type 2 transmembrane protein $\mathrm{TNF} \alpha$ was identified as a substrate for SPPL2a and SPPL2b [34, 35]. To elucidate whether GxGD proteases in general use a common mechanism to cleave their substrates within the hydrophobic transmembrane domains, Fluhrer et al. [34] closer investigated the cleavage of TNF $\alpha$ by SPPL2b, using mass spectrometric analysis and radiosequencing. Two cleavage products were identified. An intracellular peptide (TNF $\alpha$ ICD) in the cell lysate and a secreted peptide 


\section{Extracellular Space}

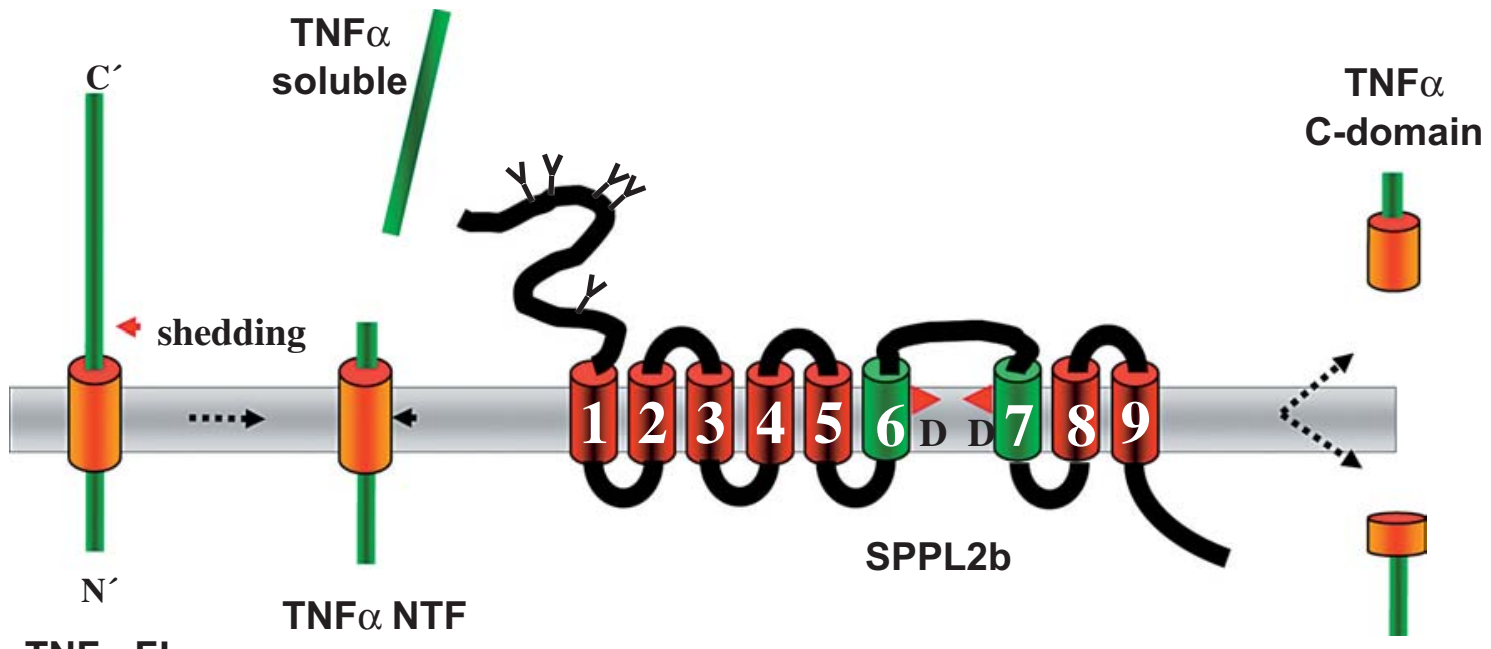

TNF $\alpha$ FL

TNF $\alpha$ ICD

\section{Cytosol}

\section{Extracellular Space}

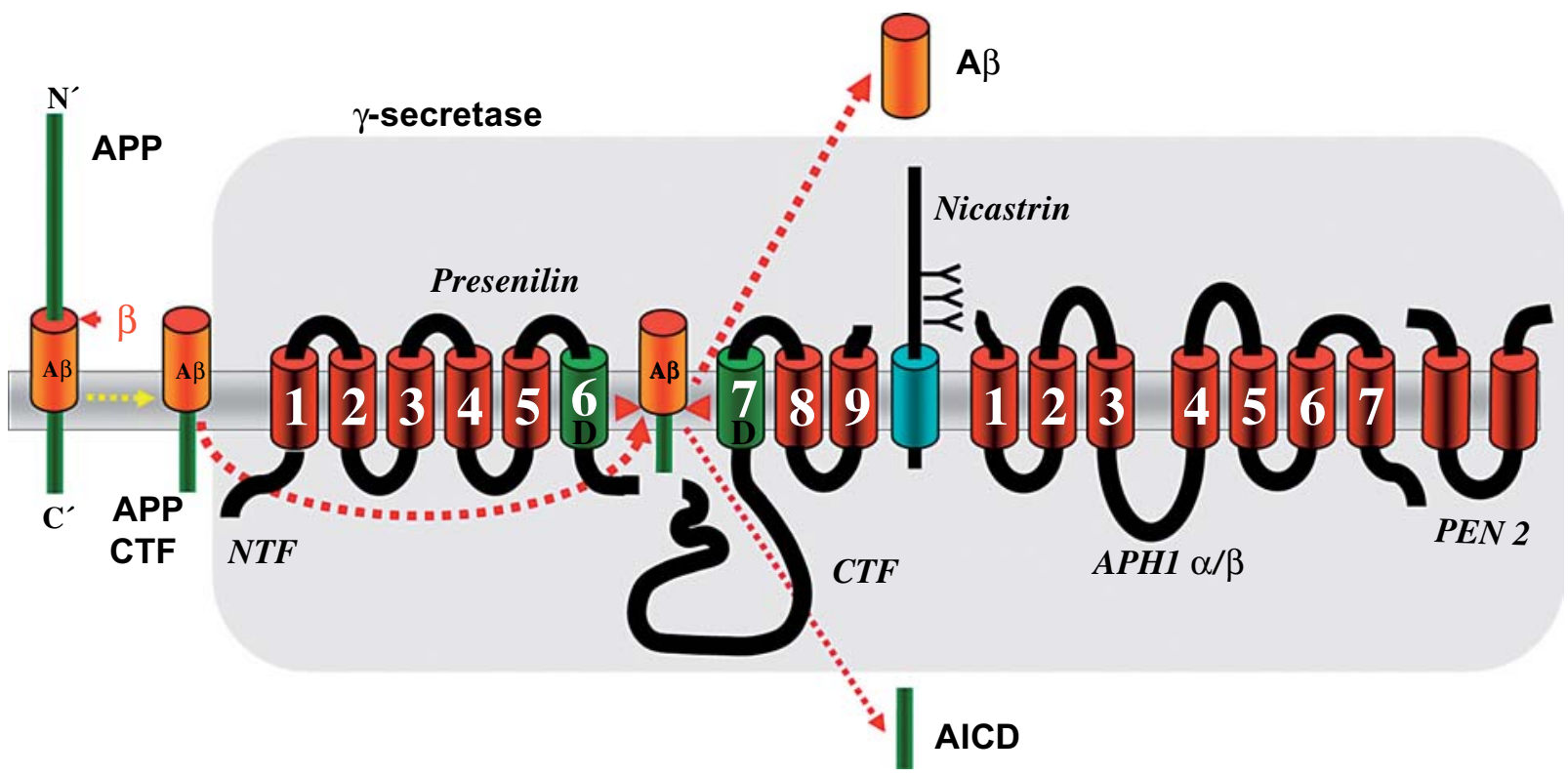

Cytosol

2

Fig. 1. Schematic representation of the TNF $\alpha$ processing by SPPL2b.

Fig. 2. Schematic representation of the APP processing by $\gamma$-secretase. 
(TNF $\alpha$ C-domain) (fig. 1) in the cell culture medium were detected. Strikingly, the two cleavage products were not the result of a single cleavage, but were rather separated by a few amino acids, consequently suggesting a dual or even multiple cleavage event used by SPPL2b to release the transmembrane domain of TNF $\alpha$. Interestingly, the TNF $\alpha$ ICD, generated by SPPL $2 b$, is involved in the transcriptional regulation of IL-12 [35]. Thus, SPPL2b is not only a novel intramembrane protease of the GxGD-type, but is also critically required for a so far unknown signaling pathway.

\section{$\gamma$-Secretase versus SPPLs: Relatives with Similarities and Differences}

The SPPLs have been identified as an additional family member of the GxGD proteases. As for the PSs mutation of the critical aspartate within the GxGD motive of SPPLs leads to a complete loss of proteolytic activity [31, 34]. SPP/SPPL activity is massively increased upon overexpression of a single cDNA, suggesting that these proteases are active as monomers or homodimers [30], which do not require additional binding proteins for their activity. Sole overexpression of PSs on the other hand does not cause an increased proteolytic activity of $\gamma$-secretase, because $\gamma$-secretase requires complex formation of PS, Aph1, Nct, and Pen-2 to be active [11].

Although both protease families show fundamental differences with respect to complex formation and primary structure, they exhibit surprising similarity in the cleavage pattern of their substrates. SPPL2b, like $\gamma$-secretase, performs multiple intramembrane cleavages separated by a number of amino acids. In analogy to $\gamma$-secretase, the cleavage of TNF $\alpha$ by SPPL2b leads to an intracellular domain (TNF $\alpha$ ICD) and to a secreted peptide (TNF $\alpha$ Cdomain) (fig. 1). These fragments correspond to the APP intracellular domain (ICD) and amyloid $\beta$-peptide, respectively (fig. 2). These findings may suggest a common cleavage mechanism for intramembrane proteolysis of GxGD type aspartyl proteases.

PS1 only cleaves type 1 transmembrane proteins while SPPL2b seems to cleave exclusively type 2-oriented trans- membrane proteins. Accordingly, the membrane topology of SPPL2b compared to PS1 is reversed. It is therefore tempting to speculate that the cleavage pattern of SPPL $2 b$ may include a $\gamma$-cleavage (after amino acid 34 and 39) and an $\varepsilon$-like cut [36] (after amino acid 49) as well as a $\zeta$-like cleavage [37] (after amino acid 51) at the luminal side of the membrane. Moreover, intramembrane proteolysis of TNF $\alpha$ by SPPL2b generates a cytoplasmic cleavage product, which is required for cellular signaling [35]. A similar cellular signaling function is well established for the cleavage of Notch by $\gamma$-secretase [38].

The question arises of how one protease activity can cut its substrate at several sites. Like presenilin [39], the catalytically active component of the $\gamma$-secretase complex, SPP and all SPPLs appear to occur as homodimers $[30,31]$. Moreover, at least for SPP, it has been shown that dimerization facilitates the binding of an active-site directed photoaffinity labeled $\gamma$-secretase inhibitor, suggesting that dimerization is required to form the fully active catalytic site of SPP [30].

If SPP or SPPL3 process their substrates by a similar mechanism in vivo remains to be demonstrated. However, recent in vitro experiments using an artificial substrate suggest that SPP may cleave at predominantly one side within the membrane, although additional cleavages could not be excluded [29].

Taken together, the remarkable similarities of SPPL $2 b$ and $\gamma$-secretase regarding their cleavage mechanisms together with their role in signaling and gene regulation suggest a common concept of intramembrane proteolysis. It is now important find out why $\gamma$-secretase requires additional cofactors for its biological function, while all SPP family members apparently do not require such proteins.

\section{Acknowledgements}

This work was supported by the APOPIS Program (Abnormal proteins in the pathogenesis of neurodegenerative disorders) - An integrated project funded by the EU under the Sixth Framework Programme; Priority: Life Science for Health. We thank Dr. Bernd Sommer and the Boehringer Ingelheim KG for the APOPIS award for young investigators (to R.F.).

\section{References}

1 Brown MS, Ye J, Rawson RB, Goldstein JL: Regulated intramembrane proteolysis: a control mechanism conserved from bacteria to humans. Cell 2000;100:391-398.

Common Cleavage Mechanism of GxGD Type Proteases
2 Weihofen A, Martoglio B: Intramembranecleaving proteases: controlled liberation of functional proteins and peptides from membranes. Trends Cell Biol 2003;13:71-78.
3 Urban S, Lee JR, Freeman M: Drosophila rhomboid-1 defines a family of putative intramembrane serine proteases. Cell 2001; 107:173-182. 
4 Lee JR, Urban S, Garvey CF, Freeman M: Regulated intracellular ligand transport and proteolysis control egf signal activation in drosophila. Cell 2001;107:161-171.

5 Wolfe MS, Xia W, Ostaszewski BL, Diehl TS, Kimberly WT, Selkoe DJ: Two transmembrane aspartates in presenilin-1 required for presenilin endoproteolysis and $\gamma$-secretase activity. Nature 1999;398:513-517.

6 Weihofen A, Lemberg MK, Ploegh HL, Bogyo M, Martoglio B: Release of signal peptide fragments into the cytosol requires cleavage in the transmembrane region by a protease activity that is specifically blocked by a novel cysteine protease inhibitor. J Biol Chem 2000;275:30951-30956.

7 Weihofen A, Binns K, Lemberg MK, Ashman K, Martoglio B: Identification of signal peptide peptidase, a presenilin-type aspartic protease. Science 2002;296:2215-2218.

8 Selkoe D, Kopan R: Notch and Presenilin: regulated intramembrane proteolysis links development and degeneration. Annu Rev Neurosci 2003;26:565-597.

9 Haass C, Steiner H: Alzheimer disease $\gamma$ secretase: a complex story of GxGD-type presenilin proteases. Trends Cell Biol 2002; 12:556-562.

10 Haass C: Take five-BACE and the $\gamma$-secretase quartet conduct Alzheimer's amyloid $\beta$ peptide generation. EMBO J 2004;23:483488.

11 Edbauer D, Winkler E, Regula JT, Pesold B, Steiner $\mathrm{H}$, Haass C: Reconstitution of $\gamma$ secretase activity. Nat. Cell Biol 2003;5:486488.

12 Takasugi N, Tomita T, Hayashi I, Tsuruoka M, Niimura M, Takahashi Y, Thinakaran G, Iwatsubo T: The role of presenilin cofactors in the $\gamma$-secretase complex. Nature 2003; 422:438-441.

13 Kimberly WT, LaVoie MJ, Ostaszewski BL, Ye W, Wolfe MS, Selkoe DJ: $\gamma$-Secretase is a membrane protein complex comprised of presenilin, nicastrin, Aph-1, and Pen-2. Proc Natl Acad Sci USA 2003;100:6382-6387.

14 Kim SH, Sisodia SS: A sequence within the first transmembrane domain of PEN-2 is critical for PEN-2-mediated endoproteolysis of presenilin 1. J Biol Chem 2005;280:19922001.

15 Steiner H, Duff K, Capell A, Romig H, Grim MG, Lincoln S, Hardy J, Yu X, Picciano M, Fechteler K, Citron M, Kopan R, Pesold B, Keck S, Baader M, Tomita T, Iwatsubo T, Baumeister R, Haass C: A loss of function mutation of presenilin-2 interferes with amyloid $\beta$-peptide production and Notch signaling. J Biol Chem 1999;274:28669-28673.

16 Zhang Z, Nadeau P, Song W, Donoviel D, Yuan M, Bernstein A, Yankner BA: Presenilins are required for $\gamma$-secretase cleavage of $\beta A P P$ and transmembrane cleavage of Notch-1. Nat. Cell Biol 2000;2:463-465.
17 Herreman A, Serneels L, Annaert W, Collen D, Schoonjans L, De Strooper B: Total inactivation of $\gamma$-secretase activity in presenilindeficient embryonic stem cells. Nat. Cell Biol 2000;2:461-462.

18 De Strooper B: Aph-1, pen-2, and nicastrin with presenilin generate an active $\gamma$-secretase complex. Neuron 2003;38:9-12.

19 Steiner H, Kostka M, Romig H, Basset G, Pesold B, Hardy J, Capell A, Meyn L, Grim MG, Baumeister R, Fechteler K, Haass C: Glycine 384 is required for presenilin-1 function and is conserved in polytopic bacterial aspartyl proteases. Nat. Cell Biol 2000;2:848-851.

20 Martoglio B, Golde TE: Intramembranecleaving aspartic proteases and disease: presenilins, signal peptide peptidase and their homologs. Hum Mol Genet 2003;12 Spec No 2:R201-R206.

21 Wolfe MS, Kopan R: Intramembrane proteolysis: theme and variations. Science 2004; 305:1119-1123.

22 LaPointe CF, Taylor RK: The type 4 prepilin peptidases comprise a novel family of aspartic acid proteases. J Biol Chem 2000;275: 1502-1510.

23 Kimberly WT, Xia W, Rahmati T, Wolfe MS Selkoe DJ: The transmembrane aspartates in presenilin 1 and 2 are obligatory for $\gamma$-secretase activity and amyloid $\beta$-protein generation. J Biol Chem 2000;275:3173-3178.

24 Li YM, Lai MT, Xu M, Huang Q, DiMuzioMower J, Sardana MK, Shi XP, Yin KC, Shafer JA, Gardell SJ: Presenilin 1 is linked with $\gamma$-secretase activity in the detergent solubilized state. Proc Natl Acad Sci USA 2000;97: 6138-6143.

25 Esler WP, Kimberly WT, Ostaszewski BL, Diehl TS, Moore CL, Tsai J-Y, Rahmati T, Xia W, Selkoe DJ, Wolfe MS: Transition-state analogue inhibitors of $\gamma$-secretase bind directly to presenilin-1. Nat Cell Biol 2000;2:428433.

26 Wrigley JD, Nunn EJ, Nyabi O, Clarke EE, Hunt P, Nadin A, De Strooper B, Shearman MS, Beher D: Conserved residues within the putative active site of gamma-secretase differentially influence enzyme activity and inhibitor binding. J Neurochem 2004;90:13121320.

27 Ponting CP, Hutton M, Nyborg A, Baker M, Jansen K, Golde TE: Identification of a novel family of presenilin homologues. Hum Mol Genet 2002;11:1037-1044.

28 Grigorenko AP, Moliaka YK, Korovaitseva GI, Rogaev EI: Novel class of polytopic proteins with domains associated with putative protease activity. Biochemistry (Mosc) 2002; 67:826-835.

29 Sato T, Nyborg AC, Iwata N, Diehl TS, Saido TC, Golde TE, Wolfe MS: Signal peptide peptidase: biochemical properties and modulation by nonsteroidal anti-inflammatory drugs. Biochemistry 2006;45:8649-8656.
30 Nyborg AC, Kornilova AY, Jansen K, Ladd TB, Wolfe MS, Golde TE: Signal peptide peptidase forms a homodimer that is labeled by an active site-directed gamma-secretase inhibitor. J Biol Chem 2004;279:15153-15160.

31 Krawitz P, Haffner C, Fluhrer R, Steiner H, Schmid B, Haass C: Differential localization and identification of a critical aspartate suggest non-redundant proteolytic functions of the presenilin in homologues SPPL2b and SPPL3. J Biol Chem 2005.

32 Dev KK, Chatterjee S, Osinde M, Stauffer D, Morgan H, Kobialko M, Dengler U, Rueeger H, Martoglio B, Rovelli G: Signal peptide peptidase dependent cleavage of type II transmembrane substrates releases intracellular and extracellular signals. Eur J Pharmacol 2006;540:10-17.

33 Nyborg AC, Jansen K, Ladd TB, Fauq A, Golde TE: A signal peptide peptidase (SPP) reporter activity assay based on the cleavage of type II membrane protein substrates provides further evidence for an inverted orientation of the SPP active site relative to presenilin. J Biol Chem 2004;279:43148-43156.

34 Fluhrer R, Grammer G, Israel L, Condron MM, Haffner C, Friedmann E, Bohland C, Imhof A, Martoglio B, Teplow DB, Haass C: A gamma-secretase-like intramembrane cleavage of TNFalpha by the GxGD aspartyl protease SPPL2b. Nat Cell Biol 2006;8:894896.

35 Friedmann E, Hauben E, Maylandt K, Schleeger S, Vreugde S, Lichtenthaler SF, Kuhn PH, Stauffer D, Rovelli G, Martoglio B: SPPL2a and SPPL2b promote intramembrane proteolysis of TNFalpha in activated dendritic cells to trigger IL-12 production. Nat Cell Biol 2006;8:843-848.

36 Okochi M, Steiner H, Fukumori A, Tanii H, Tomita T, Tanaka T, Iwatsubo T, Kudo T, Takeda M, Haass C: Presenilins mediate a dual intramembranous gamma-secretase cleavage of Notch-1. Embo J 2002;21:5408 5416.

37 Zhao G, Cui MZ, Mao G, Dong Y, Tan J, Sun $\mathrm{L}, \mathrm{Xu} \mathrm{X}$ : gamma-cleavage is dependent on zeta -cleavage during the proteolytic processing of amyloid precursor protein within its transmembrane domain. J Biol Chem 2005.

38 Mumm JS, Kopan R: Notch signaling: from the outside in. Dev Biol 2000;228:151-165.

39 Schroeter $\mathrm{EH}$, Ilagan MX, Brunkan $\mathrm{AL}$, Hecimovic S, Li YM, Xu M, Lewis HD, Saxena MT, De Strooper B, Coonrod A, Tomita T, Iwatsubo T, Moore CL, Goate A, Wolfe MS, Shearman M, Kopan R: A presenilin dimer at the core of the $\gamma$-secretase enzyme: insights from parallel analysis of Notch 1 and APP proteolysis. Proc Natl Acad Sci USA 2003;100:13075-13080 